\title{
Current Conveyor Based Window Comparator Circuits
}

\author{
Sudhanshu Maheshwari \\ Department of Electronics Engineering, Zakir Husain College of Engineering and Technology, Aligarh, India \\ Correspondence should be addressed to Sudhanshu Maheshwari; sudhanshu_maheshwari@rediffmail.com
}

Received 6 August 2016; Accepted 29 September 2016

Academic Editor: Gorazd Stumberger

Copyright (C) 2016 Sudhanshu Maheshwari. This is an open access article distributed under the Creative Commons Attribution License, which permits unrestricted use, distribution, and reproduction in any medium, provided the original work is properly cited.

\begin{abstract}
This paper introduces a new window comparator circuit utilizing a new current conveyor and two diodes, operable at $\pm 1.25 \mathrm{~V}$ and capable of accurately detecting the voltage windows. Another modified circuit with distinct binary levels suited for automatic control applications is also suggested. Exhaustive simulation results showing detection of windows, as small as $50 \mathrm{mV}$ and as high as $1 \mathrm{~V}$, are included. Comparisons are further drawn with the traditional operational amplifier based circuit and the new circuit is found to benefit from the use of current-mode active element, namely, Extra-X Current Controlled Current Conveyor. The proposed theory is well supported through simulation results.
\end{abstract}

\section{Introduction}

Analog signal processing utilizing complementary metal oxide semiconductor (CMOS) building blocks has recently been identified as a potential area of research, with a wide variety of applications being continuously reported based on the assorted current-mode building blocks [1-3]. Window comparators are a class of nonlinear circuits used to establish the confinement of a signal within a specified voltage range, called the "window." There are two types of window comparator circuits, namely, the one which senses the input signal to produce a high output for the signal confinement within the window and the second type which produces a low output for the signal confinement within the window. The output of the circuit for the signal level falling outside the specified window range is "low" in the former and "high" in the latter case. Window comparator circuits find wide range of applications, for instance, to monitor the battery voltage lying within the desired range, in industrial alarms, in level detectors and controls, in digital computers, in production line-testing to sort circuits that fail to meet a specified tolerance, and so forth. The commonly used window comparators are built around operational amplifiers, two in number, along with two diodes [4]. These circuits have well-known limitations associated with the voltage operational amplifier (opamp) based circuits, namely, finite gain-bandwidth product, limited bandwidth, and slew rate, beside the requirement of two opamps themselves.

There is an urge to develop effective circuit designs employing current-mode active elements in form of current conveyors for realizing class of linear and nonlinear circuits [5-12]. For instance, a simple comparator has been realized using current conveyors [6]. However, to the best of author's investigation, a "window comparator" is not yet reported in literature, which employs current conveyors. This paper presents such a circuit which employs a new current conveyor with an extra X-stage and tuning property, namely, Extra$\mathrm{X}$ Current Controlled Current Conveyor (EXCCCII). The new circuit unlike opamp based counterparts uses a single active element and exhibits higher performance features, namely, higher frequency of operation, fewer active elements, and detection of both, small and large, magnitudes of voltage windows. Exhaustive study is carried out to validate the proposed theory through effective simulation results.

The rest of the paper is organized in the subsequent order as follows: Section 2 presents the actual circuit description; Section 3 presents the results of the proposed circuit; Section 4 draws comparisons with opamp based window detectors; Section 5 adds to the proposed circuit by offering a modified circuit with additional features; Section 6 is devoted to the discussion on possible design of the proposal using 


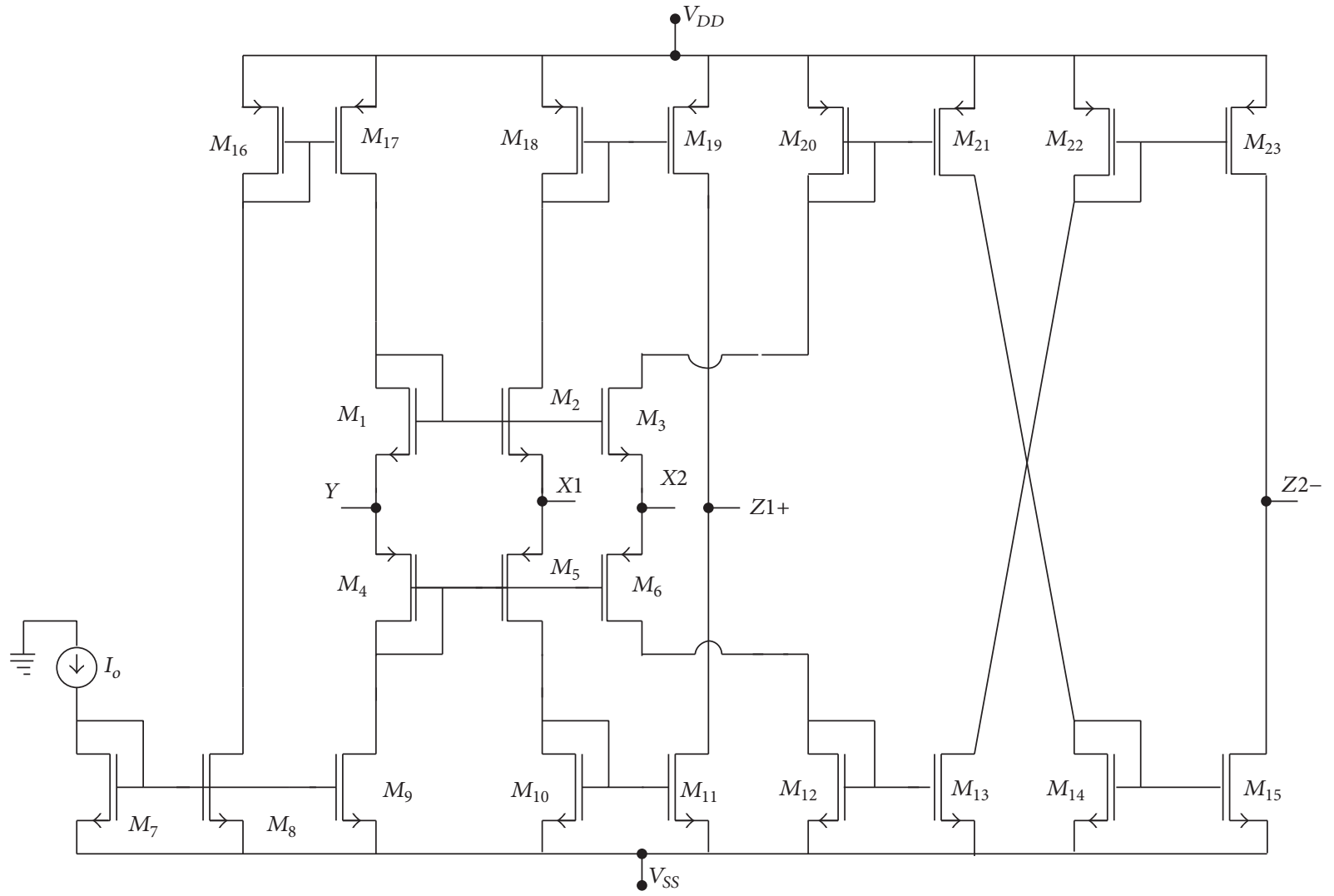

Figure 1: CMOS circuitry for Extra-X Current Controlled Current Conveyor (EXCCCII).

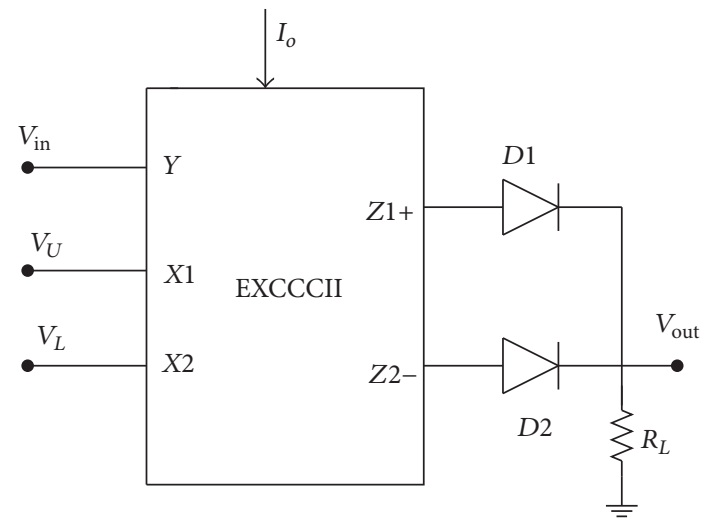

Figure 2: Proposed window comparator circuit.

commercial ICs; and Section 7 delivers conclusion to the paper.

\section{Circuit Description}

The new proposed window comparator circuit based on the new current conveyor, given in Figure 1, is shown in Figure 2. The circuit of Figure 1 is characterized by the following relationship:

$$
\begin{aligned}
i & =1,2, \\
i_{z 1+} & =i_{x 1}, \\
i_{z 2-} & =-i_{x 2} .
\end{aligned}
$$

It may be noted that the currents entering or leaving both $X$ and $Z$ terminals are taken to be positive, for positive type conveyors. It may be noted that current conveyors with positive current transfer gain benefit from simpler circuitry, compared to the ones with negative current transfer gain. At the core of circuitry are the two mixed translinear loops comprised of transistors $M_{1}$ to $M_{6}$, with intrinsic resistance $R_{x i}(i=1,2)$ as given below. It is worth pointing that saturation region is assumed for the transistors comprising the translinear loops. It may be noted that $R_{x 1}=R_{x 2}$ for the used design: $(W / L)_{2}=(W / L)_{3}$ and $(W / L)_{5}=(W / L)_{6}$ :

$$
R_{x i}=\frac{1}{\sqrt{8 \mu C_{o x}(W / L) I_{o}}} .
$$

The parameters in (2) refer to the MOS transistors comprising the translinear loop, and $I_{o}$ is the bias current of EXCCCII. The two currents flowing in the $Z$ stages are given as

$$
\begin{aligned}
& I_{Z 1+}=\frac{\left(V_{\text {in }}-V_{U}\right)}{R_{x 1}}, \\
& I_{Z 2-}=-\frac{\left(V_{\text {in }}-V_{L}\right)}{R_{x 2}} .
\end{aligned}
$$

$$
\begin{aligned}
i_{y} & =0, \\
V_{x i} & =V_{y}+i_{x i} R_{x i},
\end{aligned}
$$


The circuit output is the voltage developed across $R_{L}$, which depends on the conduction of current through either of the two diodes. Therefore, the output voltage can be expressed as

$$
V_{\text {out }}=\left(I_{Z 1+}+I_{Z 2-}\right) R_{L} \text {. }
$$

It may be noted that either both diodes are off (making output "low") or only one of the two diodes is on at a time (making output "high"); hence the output effectively depends on only one of the two currents in (4). The circuit operation can be described by the following expression:

(i) $V_{L} \leq V_{\text {in }} \leq V_{U}: D 1, D 2$ both off; $V_{\text {out }}$ is low,

(ii) $V_{\text {in }} \leq V_{L}: D 1$ off, $D 2$ on; $V_{\text {out }}$ is high,

(iii) $V_{\text {in }} \geq V_{U}: D 1$ on, $D 2$ off; $V_{\text {out }}$ is high.

Equation (5) can be interpreted as follows.

For $V_{\text {in }}$ values lying in between $V_{L}$ and $V_{U}$, the output remains "low," as none of the diodes turn on in these cases. The output of the window detector is "high" for values of $V_{\text {in }}$ which are either below $V_{L}$ when $D 2$ switches on or in excess to $V_{U}$, when $D 1$ is on.

Thus the circuit detects the window between the two threshold levels, namely, $V_{L}$ and $V_{U}$, by providing a "low" output. If the signal deviates from this window, the output becomes "high." Thus, the proposed circuit falls in the category of second type of window detectors, as exemplified in the earlier section, the one which produces a "low" output for the signal confinement within the "window."

\section{Simulation Results}

The CMOS implementation of Extra-X Current Controlled Current Conveyor (EXCCCII) is used for verification of the proposed circuit with a supply voltage of $\pm 1.25 \mathrm{~V}$ and $0.25 \mu \mathrm{m}$ process parameters. The bias current $I_{o}$ was taken as $100 \mu \mathrm{A}$. For diodes some important parameters used were as follows: $\mathrm{IS}=5 e-8 \mathrm{~A}, \mathrm{BV}=7 \mathrm{~V}, \mathrm{IBV}=1 e-5 \mathrm{~A}, M=0.5$, CJO $=0.18 \mathrm{pF}$, and $\mathrm{RS}=6 \Omega$. The $\mathrm{DC}$ transfer characteristics showing the input, threshold levels $\left(V_{U}=0.5 \mathrm{~V}, V_{L}=-0.5 \mathrm{~V}\right)$, and the output are given in Figure 3. The output is found to be "low" for the signal values within the window but becomes "high" when the signal falls outside the window. The input signal along with the two threshold levels used and the output of the circuit are also shown in Figure 4, justifying the theoretical predictions. Accuracy of the circuit is further tested by reducing the window size from $1 \mathrm{~V}$ to $50 \mathrm{mV}\left(V_{U}=\right.$ $0.5 \mathrm{~V}, V_{L}=0.45 \mathrm{~V}$ ), and the result is shown in Figure 5, which confirms the assertion. Thus the circuit is good for detecting both voltage windows as small as $50 \mathrm{mV}$ and as high as $1 \mathrm{~V}$, a feature not exhibited in a very elegant circuit available in literature [10].

\section{Comparative Study}

As far as the comparison of the proposed circuit with opamp based ones is concerned, several features are worth mentioning based on the known facts and simulation studies.
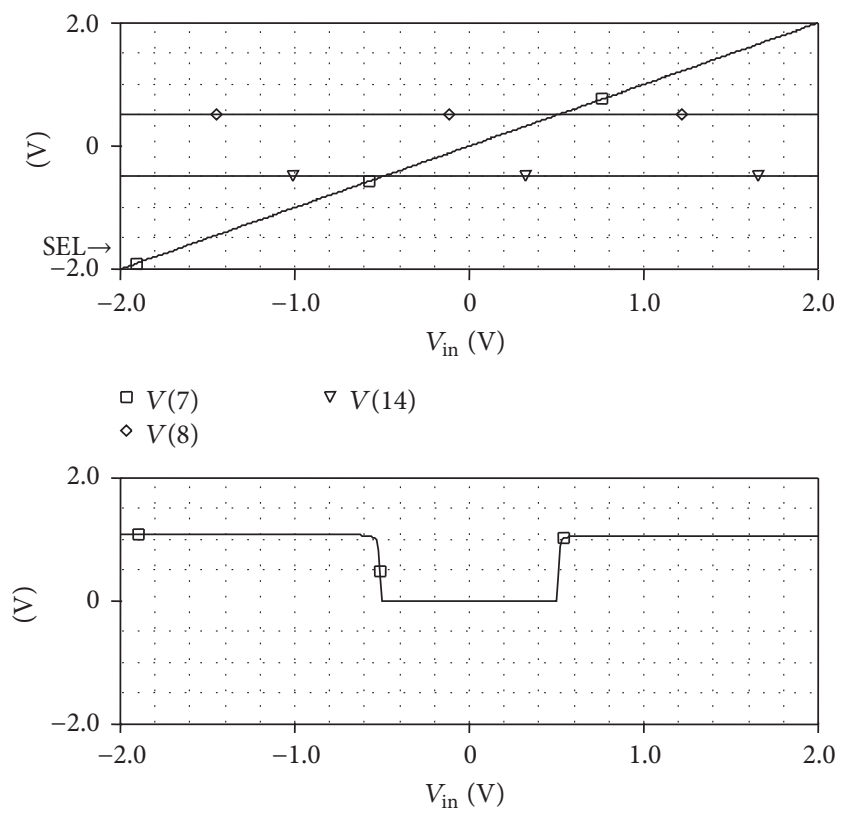

ㅁ $V(30)$

Figure 3: First plot showing input $\{V(7)\}$ and threshold levels $\left\{V(8)=V_{U}=0.5 \mathrm{~V} \& V(14)=V_{L}=-0.5 \mathrm{~V}\right\}$; second plot showing the output $\{V(30)\}$ transfer characteristics.
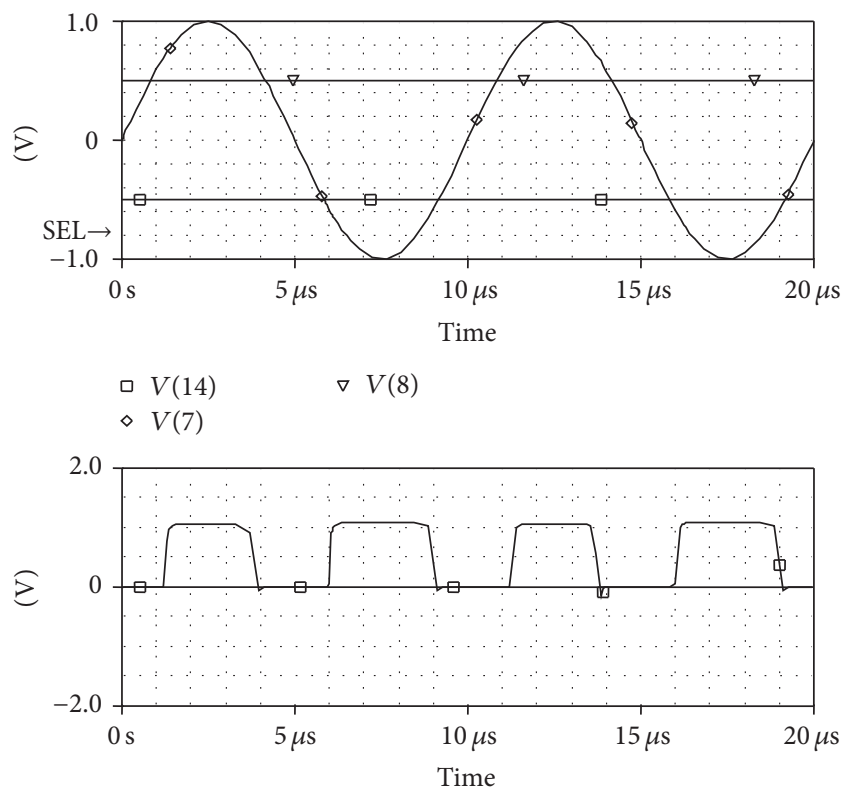

ㅁ $V(30)$

FIGURE 4: First plot showing input $\{V(7)\}$ and thresholds $\{V(14)=$ $\left.V_{L}=-0.5 \mathrm{~V} ; V(8)=V_{U}=0.5 \mathrm{~V}\right\}$; second plot showing output of proposed circuit at $100 \mathrm{KHz}$.

(i) Firstly, opamp based circuit uses two opamps [4, 13] as against a single EXCCCII used in the proposed circuit.

(ii) The tunable nature of EXCCCII allows for output current adjustment, by way of varying bias current 


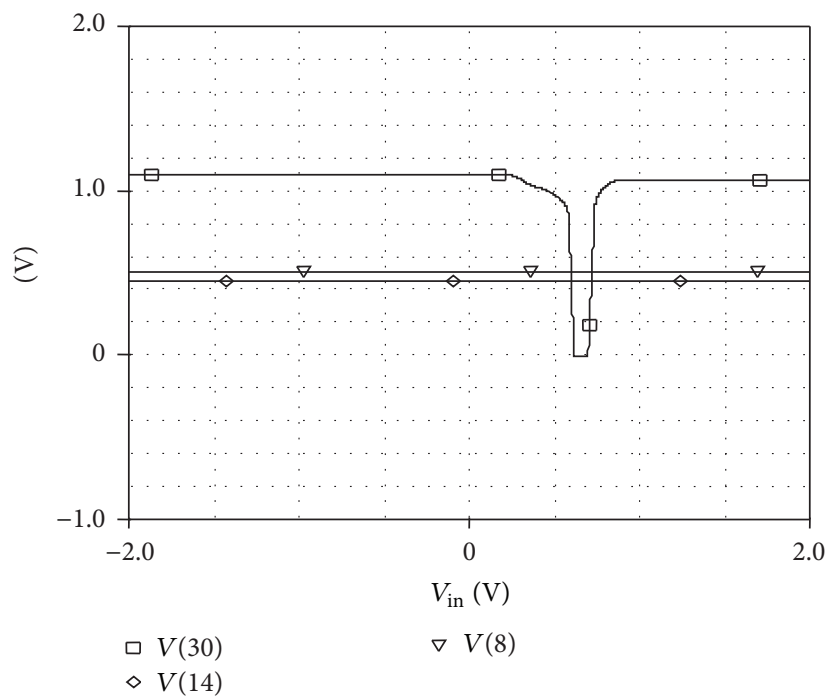

Figure 5: Transfer characteristics showing $50 \mathrm{mV}$ window detection $\{V(30)\}$ for the threshold levels $\left\{V(14)=V_{L}=0.45 \mathrm{~V} \& V(8)=V_{U}=\right.$ $0.5 \mathrm{~V}\}$.
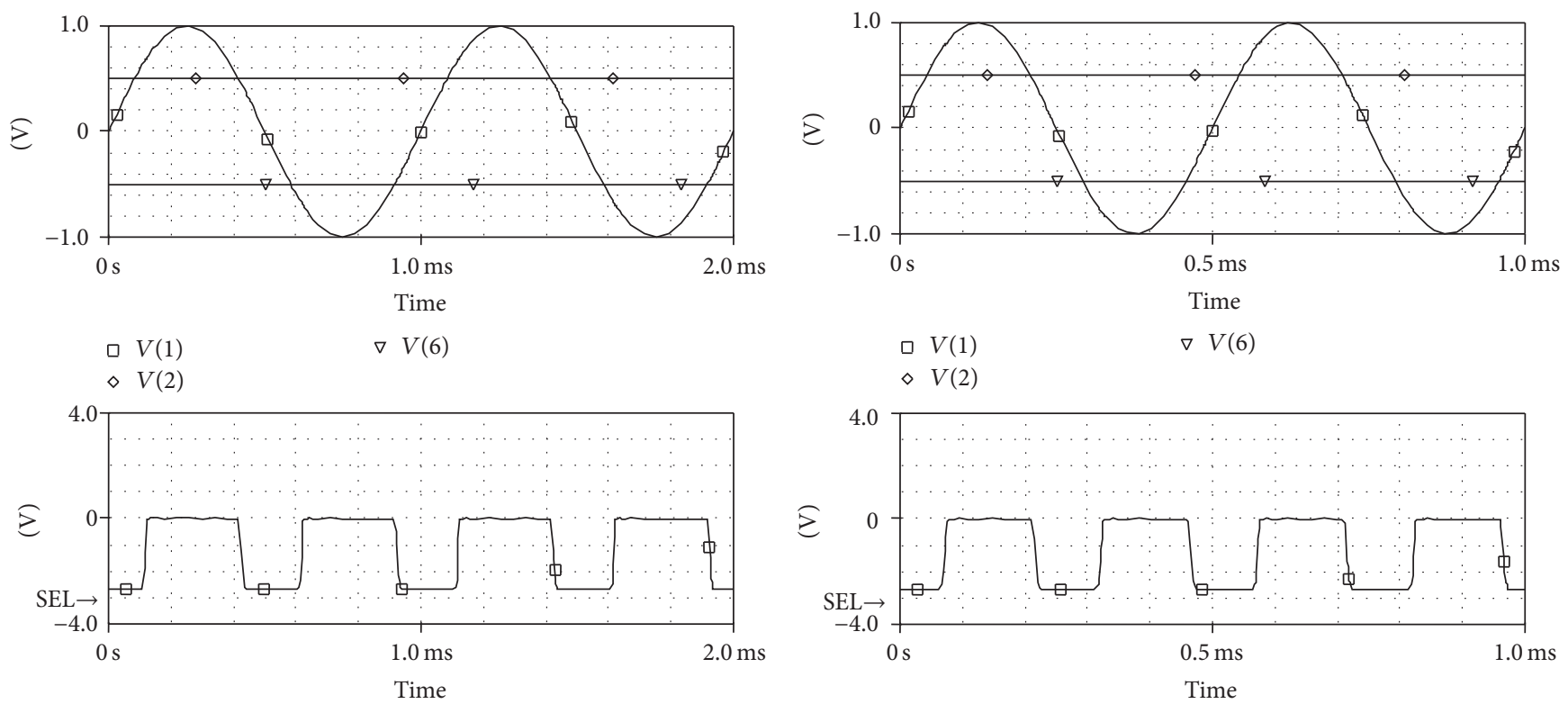

$\square(8)$

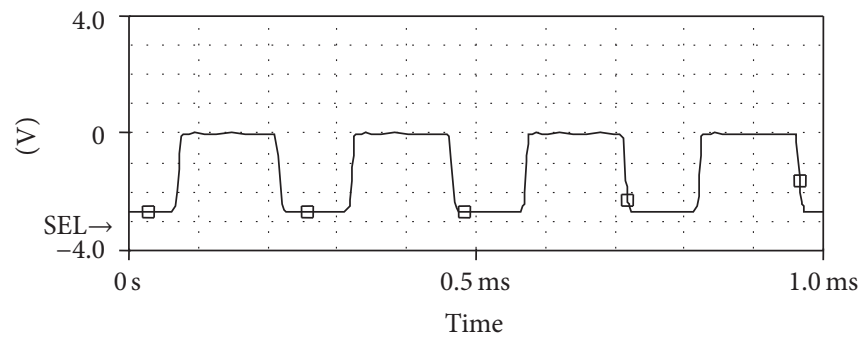

口 $V(8)$

(a)

(b)

FIGURE 6: (a) Simulation result for opamp (UA741) based design of window comparator at $1 \mathrm{KHz}$ : first plot showing input $\{V(1)\}$ and threshold levels $\left\{V(2)=V_{U}=0.5 \mathrm{~V} \& V(6)=V_{L}=-0.5 \mathrm{~V}\right\}$; second plot showing the output $\{V(8)\}$. (b) Simulation result for opamp (UA741) based design of window comparator at $2 \mathrm{KHz}$ : first plot showing input $\{V(1)\}$ and threshold levels $\left\{V(2)=V_{U}=0.5 \mathrm{~V} \& V(6)=V_{L}=-0.5 \mathrm{~V}\right\}$; second plot showing the output $\{V(8)\}$.

(hence, $R_{x}$ ), which is not possible in opamp, due to inherent nontunable nature.

(iii) The opamp based circuit [13], simulated using UA741 model, was found to exhibit satisfactory results only for few $\mathrm{KHz}$ signals for the same input and threshold levels as used for the proposed circuit, due to slew rate, as well as constant gain-bandwidth product limitations of opamp. On the other hand, the proposed circuit using EXCCCII operated for much higher frequency, namely, $100 \mathrm{KHz}$, as shown in results (Figure 4).

(iv) To further consolidate the above point, results for opamp based circuit for similar input conditions are shown in Figures 6(a) and 6(b), where frequency used is $1 \mathrm{KHz}$ and $2 \mathrm{KHz}$, respectively, for two sets of shown results. Inaccuracy in detection may be observed even 


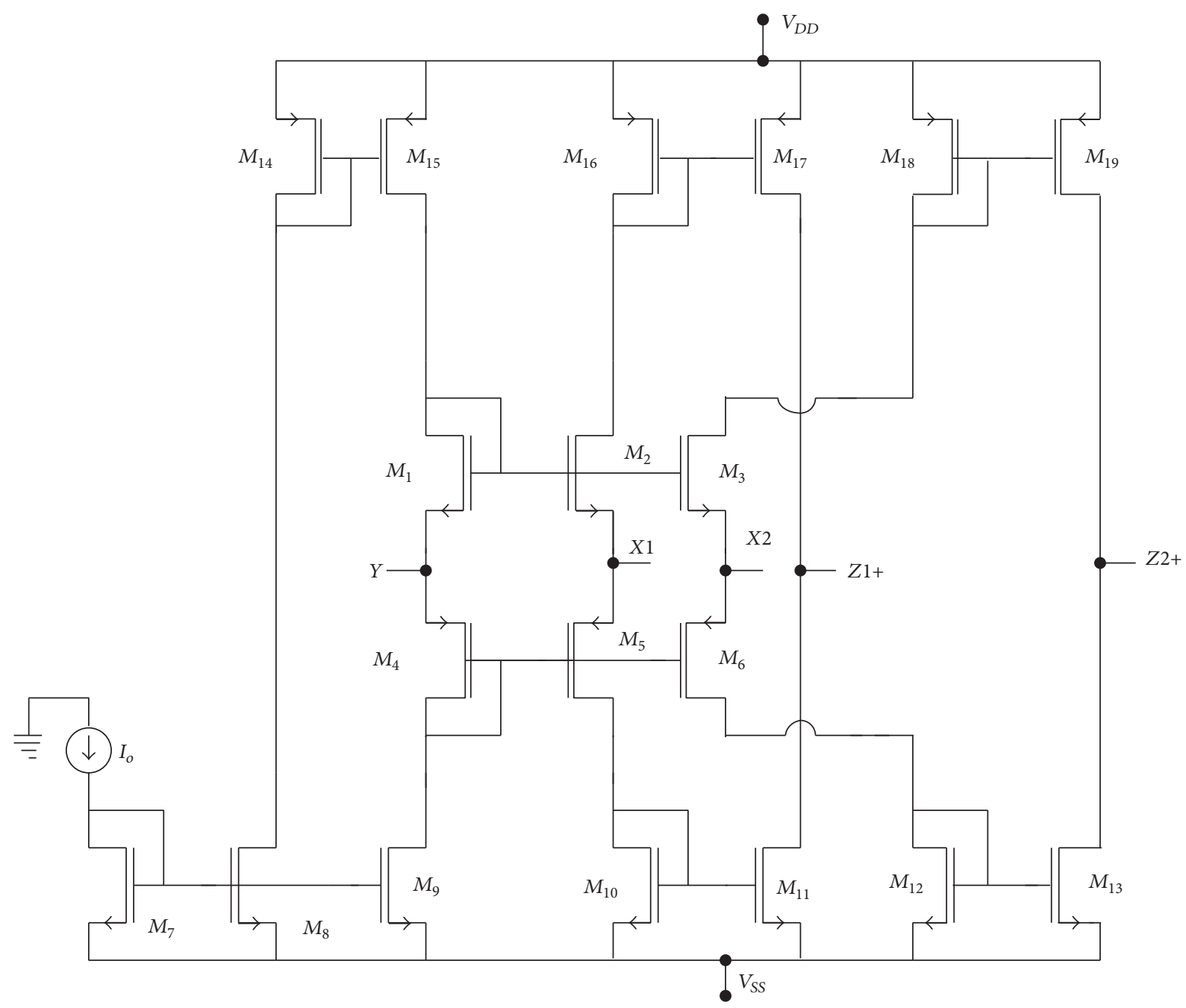

Figure 7: EXCCCII used for modified circuit.

for $2 \mathrm{KHz}$ signal. It may be noted that supply voltage for opamp based circuit used was $\pm 10 \mathrm{~V}$; frequency improvement to some extent was possible at reduced supply voltages.

(v) The detection of small size window was found to be problematic for opamp based circuit, due to offset errors, contrary to the proposed circuit, where $50 \mathrm{mV}$ was shown to be successfully detected (Figure 5).

(vi) For the general purpose opamp, like UA741, unity gain frequency is approximately $1 \mathrm{MHz}$, in contrast to the used EXCCCII, which is found to exhibit unity gain for voltage transfer and current transfer gains in the range of approximately $300 \mathrm{MHz}$.

It has to be reemphasized that the employment of currentmode active elements is to be seen as a major cause for transferring the designs based on traditional voltage mode techniques [2-4].

\section{Modified Circuit}

The proposed circuit of Figure 2 can be modified by employing $Z 2+$ (positive current transfer from X2) instead of $Z 2-$ (negative current transfer from $X 2$ ), and the $D 2$ polarity reversed, so as to obtain a window comparator capable of not only detecting the desired voltage window, but also providing distinct levels of digital outputs for out-of-window signal. Figure 7 shows the circuitry for EXCCCII with positive transfer gain from $X 2$ to $Z 2+$, described by the following relationship:

$$
\begin{aligned}
i_{y} & =0, \\
V_{x i} & =V_{y}+i_{x i} R_{x i}, \\
i & =1,2, \\
i_{z 1+} & =i_{x 1}, \\
i_{z 2+} & =i_{x 2} .
\end{aligned}
$$




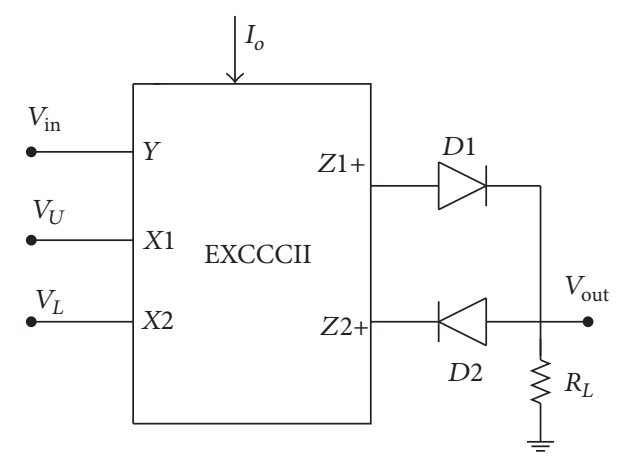

Figure 8: Modified circuit with three output levels.

Next, the actual modified circuit for window detection is shown in Figure 8. The circuit is characterized by the following:

$$
\begin{gathered}
I_{Z 1+}=\frac{\left(V_{\text {in }}-V_{U}\right)}{R_{x 1}}, \\
I_{Z 2+}=\frac{\left(V_{\text {in }}-V_{L}\right)}{R_{x 2}} .
\end{gathered}
$$
follows:

The operation of the modified circuit is summarized as

$$
\begin{aligned}
& V_{L} \leq V_{\text {in }} \leq V_{U}, \quad V_{\text {out }}=0, \\
& V_{\text {in }} \geq V_{U}, \quad V_{\text {out }}=V_{S}, \\
& V_{\text {in }} \leq V_{L}, \quad V_{\text {out }}=-V_{S} .
\end{aligned}
$$

The output is "zero" (both diodes off) for signal confinement within the window. The signal above $V_{U}$ (D1 on and $D 2$ off) causes the output to become "positive," whereas the signal below $V_{L}$ (D1 off and D2 on) causes the output to become "negative," thus providing a means of automatic feedback for corrective actions. Equation (8) is a result of the circuit modification as mentioned above. For input signals within the window range, none of the two diodes conduct, thereby keeping the output zero. For inputs greater than the upper threshold $\left(V_{U}\right), D 1$ conducts, making the output positive $\left(V_{S}\right)$, whereas, for input signal below $V_{L}, D 2$ conducts and the output becomes $-V_{S}$. Figure 9 shows the results for the modified circuit. In (8) the positive and negative outputs refer to the saturation levels, namely, $V_{S}$ and $-V_{S}$, respectively. This aspect is clearly evident from Figure 9, where the first plot shows the input signal and the two threshold levels, whereas the second plot shows the output of the modified circuit. Three levels of the outputs (zero, positive, and negative) can be seen in Figure 9, as per (8).

For the sake of completeness, the proposed window comparator and its modified version presented in this work are further compared with the most relevant works available in literature. It may again be emphasized that, to the best knowledge of author, window comparator circuit has not been presented yet, employing current conveyor or its variants [1-16]. Table 1 lists the proposed circuits' comparisons
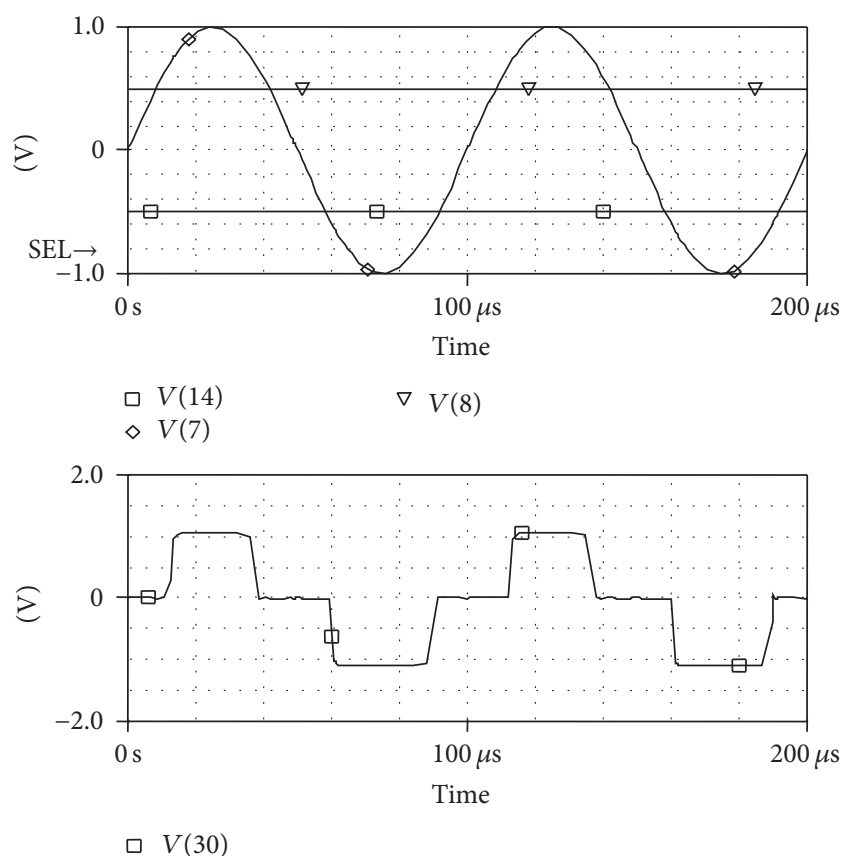

FIGURE 9: First plot showing input $\{(V(7)\}$ and thresholds $\{V(14)=$ $\left.V_{L}=-0.5 \mathrm{~V} \& V(8)=V_{U}=0.5 \mathrm{~V}\right\}$; second plot showing the output $\{V(30)\}$ of modified circuit.

with few available circuits for this electronic function. The use of current-mode building block, namely, EXCCCII, along with the features obtained makes the proposed window comparator circuits a novel enrichment to the literature on the subject.

\section{Discussion on Practicality}

It is worth considering the proposed circuits for their practicality, but for the chip count requirements matching the count realizable with traditional opamps. The complexity reduction in the set-up is thus not possible, when compared to opamp based circuits, but the performance attained using currentmode active elements is well known. Thus the advantages of employing current-mode approach are achieved. More specifically, the EXCCCII based circuit can be made IC compatible using two AD-844 chips (for circuit of Figure 8) or three AD-844 chips (for circuit of Figure 2). The use of $\mathrm{AD}-844$ may not result in complexity reduction, but the advantages of employing it have been often highlighted in open literature [14-16]. However, the use of AD-844 inbuilt models does serve the purpose of presenting the expected results of the proposed circuits, when built around commercially available chips. Figure 10 shows one such result obtained using $\mathrm{AD}-844$ models for the modified circuit of Figure 8, where input $(100 \mathrm{KHz})$ and threshold levels $\left(V_{U}=\right.$ $\left.0.5 \mathrm{~V}, V_{L}=-0.5 \mathrm{~V}\right)$ are seen in the first plot, and the second one shows the output with three distinct levels. The nature of result matches well with the result obtained using EXCCCII based circuit of Figure 7, the differences in voltage levels being attributed to the biasing voltage used. This further confirms the validity of the proposals made in the paper. 
TABLE 1: Comparative features of proposed circuits with existing works.

\begin{tabular}{|c|c|c|c|c|c|}
\hline Reference & Building block used & Number of diodes & $\begin{array}{c}\text { Accuracy of } \\
\text { window detection }\end{array}$ & Supply voltage used (V) & $\begin{array}{c}\text { Number of output } \\
\text { levels for } \\
\text { out-of-window signal }\end{array}$ \\
\hline$[4,13]$ & 2 opamps & 2 & Poor & \pm 10 typical & 1 \\
\hline [10] & 4 logic gates & - & Poor & 3 & 1 \\
\hline Proposed (Figure 2) & 1 EXCCCII & 2 & $\begin{array}{c}\text { Good } \\
(50 \mathrm{mV})\end{array}$ & \pm 1.25 & 1 \\
\hline Proposed (Figure 8) & 1 EXCCCII & 2 & $\begin{array}{c}\text { Good } \\
(50 \mathrm{mV})\end{array}$ & \pm 1.25 & 2 \\
\hline
\end{tabular}
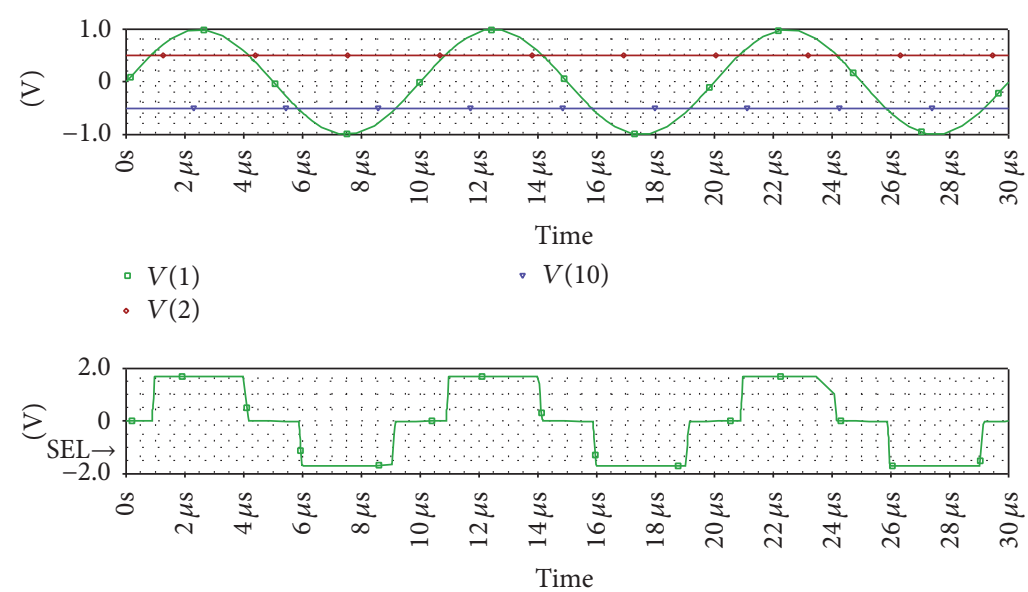

$\square V(9)$

FIGURE 10: AD-844 models' based results for the circuit of Figure 8.

Thus, the new current conveyor based circuits add to the already available knowledge on the design and applications of current conveyors [15].

\section{Conclusion}

This paper presents a new window comparator/detector circuit based on a new current conveyor, namely, Extra-X Current Controlled Conveyor and two diodes. The circuit's workability is shown through good results, for detecting voltage windows as small as $50 \mathrm{mV}$ and as high as $1 \mathrm{~V}$. Another modified circuit is further proposed which not only detects the desired window, but also provides binary levels of distinct polarity, making it useful as feedback for automatic control in industrial and commercial applications.

\section{Competing Interests}

Author declares no conflict of interests.

\section{References}

[1] B. Chaturvedi and S. Maheshwari, "Single active element based cascadable band-pass filters for Low-Q applications," Journal of Circuits, Systems and Computers, vol. 24, no. 5, Article ID 1550075, 2015.
[2] S. Maheshwari and D. Agrawal, "High performance voltagemode tunable all-pass section," Journal of Circuits, Systems and Computers, vol. 24, no. 6, Article ID 1550080, 2015.

[3] S. Maheshwari, "Current conveyor all-pass sections: brief review and novel solution," The Scientific World Journal, vol. 2013, Article ID 429391, 6 pages, 2013.

[4] D. A. Bell, Operational Amplifiers and Linear ICs, Oxford University Press, 3rd edition, 2011.

[5] A. S. Sedra and K. C. Smith, "A second-generation current conveyor and its applications," IEEE Transactions on Circuit Theory, vol. 17, no. 1, pp. 132-134, 1970.

[6] S. Maheshwari, "A canonical voltage-controlled VM-APS with grounded capacitor," Circuits, Systems, and Signal Processing, vol. 27, no. 1, pp. 123-132, 2008.

[7] T. Tsukutani, Y. Sumi, and N. Yabuki, "Versatile current-mode biquadratic circuit using only plus type CCCIIs and grounded capacitors," International Journal of Electronics, vol. 94, no. 12, pp. 1147-1156, 2007.

[8] D. Biolek, R. Senani, V. Biolkova, and Z. Kolka, "Active elements for analog signal processing: classification, review, and new proposals," Radioengineering, vol. 17, no. 4, pp. 15-32, 2008.

[9] I. A. Khan and M. T. Simsim, "An ASK modulator for RFID applications using low voltage digitally programmable CMOSCCII," in Proceedings of the 2013 Saudi International Electronics, Communications and Photonics Conference (SIECPC '13), pp. 14, Riyadh, Saudi Arabia, April 2013. 
[10] V. A. Pedroni, "Low-voltage high-speed Schmitt trigger and compact window comparator," Electronics Letters, vol. 41, no. 22, pp. 1213-1214, 2005.

[11] A. Ü. Keskin, D. Biolek, E. Hancioglu, and V. Biolková, "Current-mode KHN filter employing current differencing transconductance amplifiers," International Journal of Electronics and Communications, vol. 60, no. 6, pp. 443-446, 2006.

[12] A. M. Soliman, "Generation of third-order quadrature oscillator circuits using NAM expansion," Journal of Circuits, Systems and Computers, vol. 22, no. 7, Article ID 1350060, 13 pages, 2013.

[13] T. L. Floyd and D. Buchla, Fundamentals of Analog Circuits, Pearson, 2nd edition, 2012.

[14] S. Maheshwari and M. S. Ansari, "Catalog of realizations for dxccii using commercially available ics and applications," Radioengineering, vol. 21, no. 1, pp. 281-289, 2012.

[15] R. Senani, D. R. Bhaskar, and A. K. Singh, Current Conveyors Variants, Applications and Hardware Implementations, Springer, Berlin, Germany, 2015.

[16] R. Senani, D. R. Bhaskar, and V. K. Singh, Sinusoidal Oscillators and Waveform Generators using Modern Electronic Circuit Building Blocks, Springer, Berlin, Germany, 2016. 


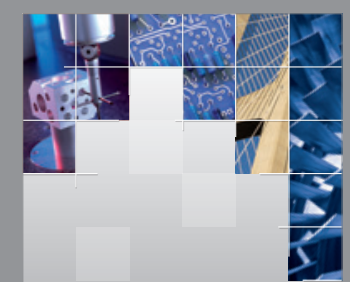

\section{Enfincering}
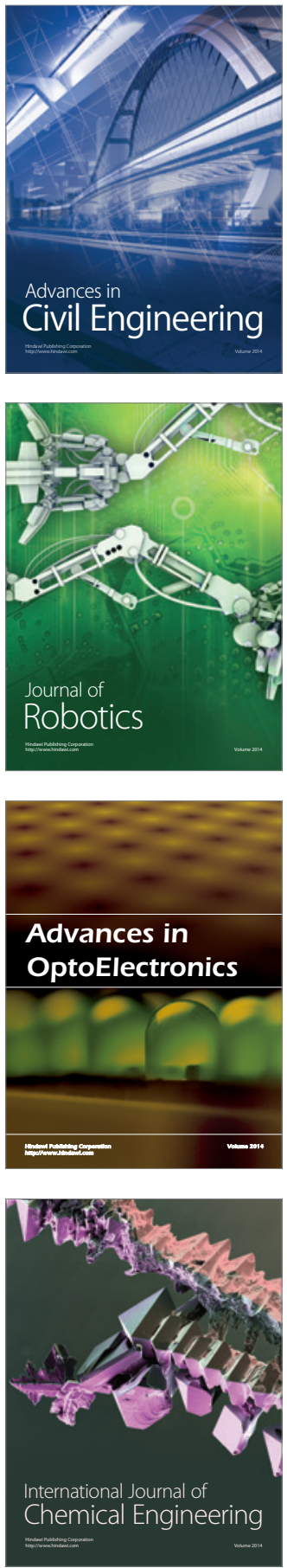

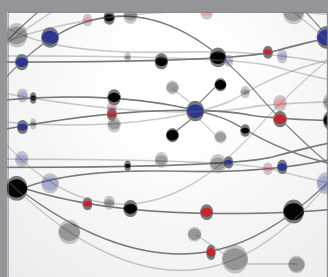

The Scientific World Journal

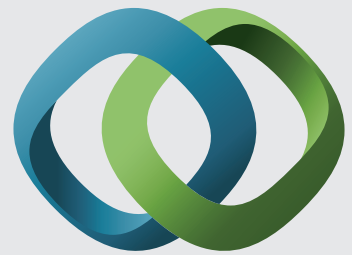

\section{Hindawi}

Submit your manuscripts at

http://www.hindawi.com
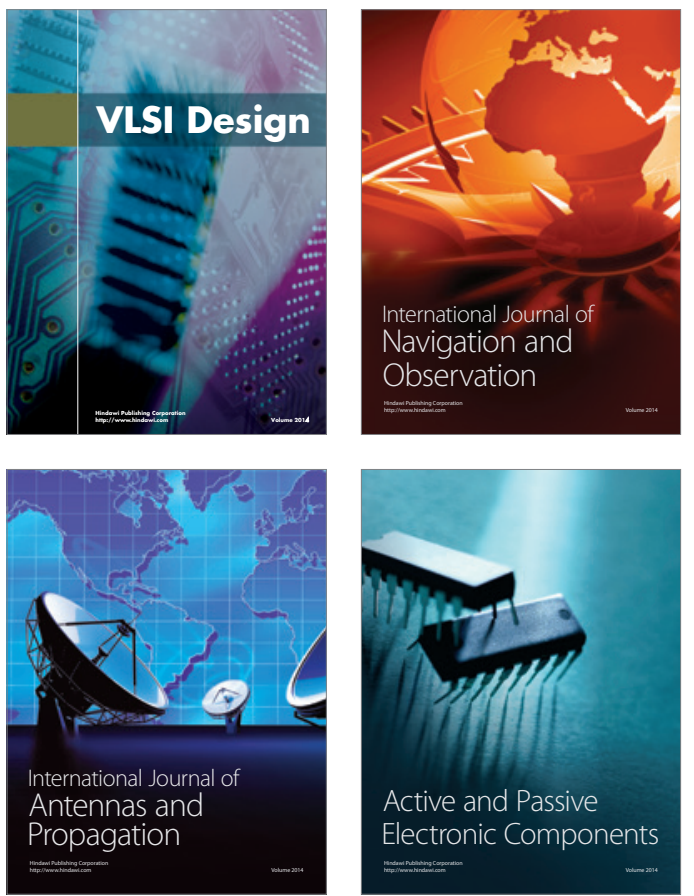
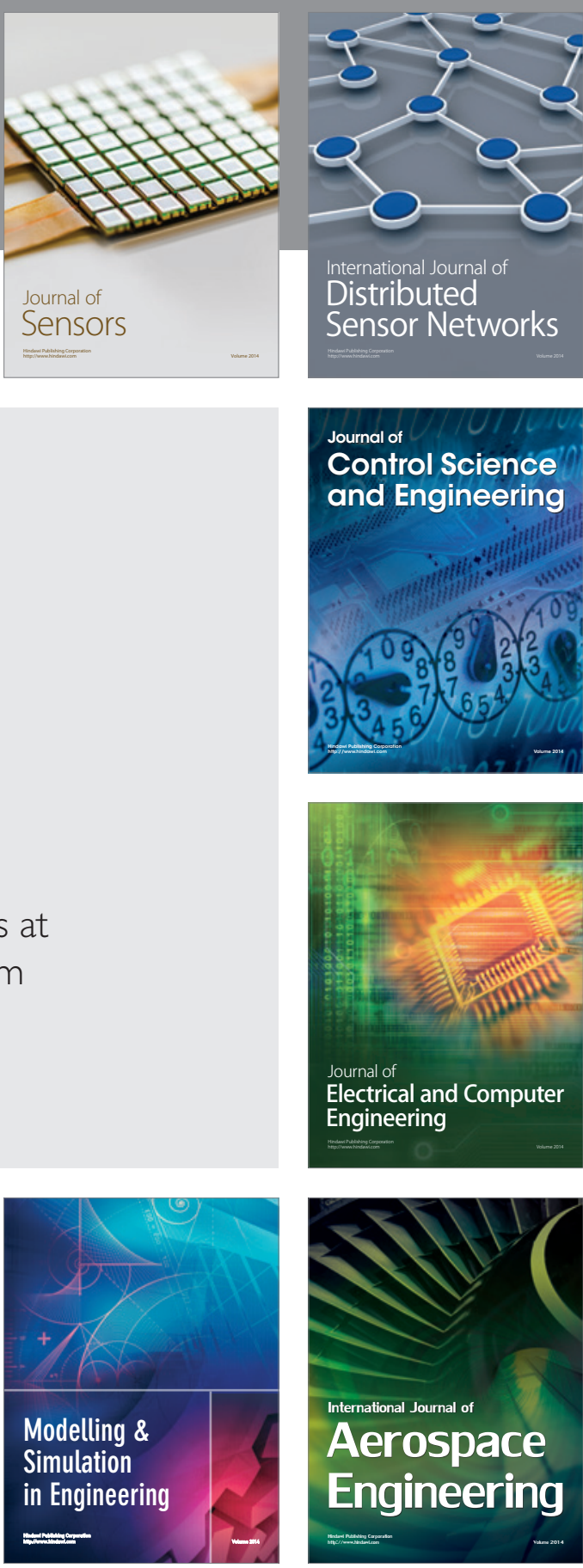

International Journal of

Distributed

Sensor Networks

Journal of

Control Science

and Engineering
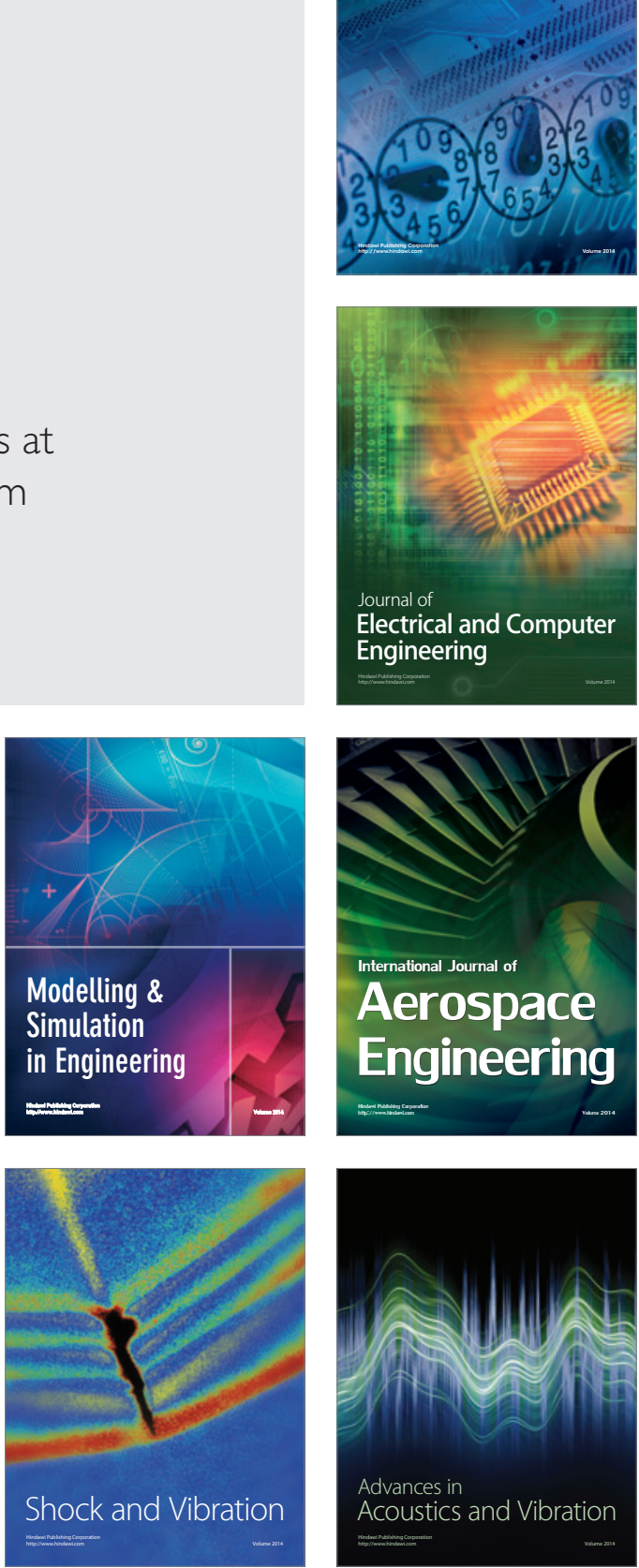